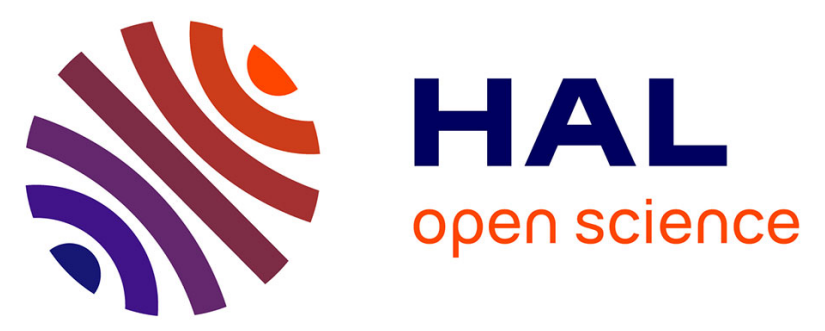

\title{
An exploratory study of energy reserves and biometry as potential tools for assessing the effects of pest management strategies on the earwig, Forficula auricularia L
}

Séverine Suchail, Adrien Le Navenant, Yvan Capowiez, Alain Thiéry, Magali Rault

\section{To cite this version:}

Séverine Suchail, Adrien Le Navenant, Yvan Capowiez, Alain Thiéry, Magali Rault. An exploratory study of energy reserves and biometry as potential tools for assessing the effects of pest management strategies on the earwig, Forficula auricularia L. Environmental Science and Pollution Research, 2018, 25 (23), pp.22766-22774. 10.1007/s11356-018-2371-x . hal-02047731

\section{HAL Id: hal-02047731}

\section{https://hal-univ-avignon.archives-ouvertes.fr/hal-02047731}

\author{
Submitted on 25 Feb 2019
}

HAL is a multi-disciplinary open access archive for the deposit and dissemination of scientific research documents, whether they are published or not. The documents may come from teaching and research institutions in France or abroad, or from public or private research centers.
L'archive ouverte pluridisciplinaire HAL, est destinée au dépôt et à la diffusion de documents scientifiques de niveau recherche, publiés ou non, émanant des établissements d'enseignement et de recherche français ou étrangers, des laboratoires publics ou privés. 
1 An exploratory study of energy reserves and biometry as potential tools for assessing the effects 25 (2) 7

\section{of pest management strategies on the earwig, Forficula auricularia $\mathrm{L}$.}

Séverine Suchail ${ }^{1}$, Adrien Le Navenant ${ }^{1,2}$, Yvan Capowiez ${ }^{3}$, Alain Thiéry ${ }^{1}$, Magali Rault ${ }^{1}$

${ }^{1}$ Univ Avignon, Aix Marseille Univ, CNRS IRD, Institut Méditerranéen de Biodiversité et d'Ecologie marine et continentale (IMBE), Pôle Agrosciences, 301 rue Baruch de Spinoza, BP 21239, 84916 Avignon cedex, France.

${ }^{2}$ INRA, Unité PSH, Equipe Ecologie de la Production Intégrée, Site Agroparc, 84914 Avignon Cedex 9, France

${ }^{3}$ INRA, UMR 1114 Environnement Méditerranéen et Modélisation des Agro-Hydrosystèmes (EMMAH), Site Agroparc, 84914 Avignon Cedex 9, France.

\section{Corresponding author:}

Séverine Suchail, UAPV, Université d'Avignon et des Pays de Vaucluse Pôle Agrosciences, 301 rue Baruch de Spinoza, BP 21239, 84916 Avignon cedex, France.

\section{E-mail address: severine.suchail@univ-avignon.fr}

\section{Tel: +33(0)490842210}




\section{Abstract}

Apple orchards are heavily treated crops and some sprayed insecticides are recognized to have toxic effects on non-target arthropods. Earwigs are important natural enemies in pip-fruit orchards and contribute to the biological control of aphids. In addition, due to their ease of capture and identification, they are an interesting potential bioindicator of the possible detrimental effects of different orchard management strategies. In this study, we measured the energy reserves and some morphological traits of $F$. auricularia L. sampled in apple orchards under management strategies (organic versus Integrated Pest Management (IPM)). We observed a significant decrease in mass (22 to $27 \%$ ), inter-eye width (3\%) and prothorax width (2 to $5 \%$ ) in earwigs from IPM compared to organic orchards. Energy body reserves also confirmed these results with a significant decrease of $48 \%$ in glycogen and 25 to $42 \%$ in lipid content in earwigs from IPM compared to organic orchards. However, the protein content was approximately $70 \%$ higher in earwigs from IPM than in organic orchards. Earwigs sampled in IPM orchards, may adapt to minimize to the adverse toxic effects of pesticide treatments using a large number of strategies, which are reflected in changes to their energy reserves. These strategies could in turn influence the population dynamics of natural enemies and impair their role in the biological control of pests in apple orchards.

Keywords: earwig, energy reserves, glycogen, lipid, protein, biometry, pest management strategy

\section{Highlights}

- Female and male from organic orchards have higher weight

- Inter-eye and prothorax widths are lower in IPM orchards

- Lipid and glycogen contents decrease in earwigs coming from IPM orchards

- Protein increase in female and male from IPM versus organic orchards 


\section{Introduction}

The United Nations Food and Agricultural Organization reported that the world's population will reach to nearly 10 billion by 2050 . This will lead to an increase in world food production in order to keep pace with the demand of this growth (Gill et al. 2014). Agricultural chemicals can enhance crop productivity. However, pesticides can also have negative effects on the environment, ecosystem and biodiversity. Pesticides can have an impact on non-target and beneficial species through direct or indirect routes, such as water contamination and runoff, pesticide residues, and by consuming food that has been sprayed (Martinou et al. 2014). The destruction of these beneficial arthropods can exacerbate pest problems as they play an important role in regulating pest population levels. In France, apple orchards are heavily treated with, on average, more than 30 pesticide applications per year (Sauphanor et al. 2009; Mazzia et al. 2015). Two pest management strategies are generally identified in commercial apple orchards: Integrated Pest Management (IPM) and organic farming. The European earwig, Forficula auricularia L. (Dermaptera: Forficulidae) is a common, sub-social and omnivorous insect in agro-ecosystems worldwide. These arthropods are commonly found in apple orchards. Adults and nymphs are nocturnal and hide during the day under shelters such as bark or in holes in the ground. They can be found in high abundance in artificial shelters and traps (Sauphanor 1992; Fountain and Harris 2015). In apple orchards, earwigs are a key biological control agent against numerous insect pests such as aphids, psyllids and spider mites (Dib et al. 2010; Debras et al. 2007; Romeu-Dalmau 2012). Their ease of capture and identification make them an interesting potential bioindicator of the intensity of pesticide use in orchards (Dib et al. 2010).

Earwigs are sensitive to different management strategies in IPM apple orchards where several pesticides can be applied, e.g., organophosphates (Ffrench-Constant and Vickerman 1985; Malagnoux et al. 2015a), pyrethroids (Badjii 2004) or neonicotinoids (Shaw and Wallis 2010; Malagnoux et al. 2015b). Other agricultural practices such as tillage and the presence and quality of hedges can also influence earwig abundance (Sharley et al. 2008; Moerkens et al. 2012) and the presence and quality of hedges (Debras et al. 2007). Management strategies in apple orchards also influence diversity in the earwig community, with $F$. auricularia being less sensitive to insecticides than $F$. pubescens (Malagnoux et al. 2015b). Studies concerning $F$. auricularia focused on its ecological role in orchards (Kölliker and Vancassel 2007; Malagnoux et al. 2015a) or the direct impact of commonly used pesticides on its populations (Ffrench-Constant and Vickerman 1985; Campos et al. 2011; Malagnoux et al. 2015a; Fountain and Harris 2015). However, there is, to our knowledge, little available data on the negative physiological effects of pesticides on energy reserves in these earwigs.

Glycogen and the lipid, triacylglycerol, are the predominant energy reserves stored in the fat bodies distributed throughout the body of the insect (Arrese and Soulage 2010). This compartment plays an essential role in energy storage and has important functions throughout the insect's life cycle including growth, timing of metamorphosis and egg development. In addition, the fat body also synthesizes most of the hemolymph proteins and circulating metabolites. Glycogen can be rapidly hydrolyzed to 
glucose in the haemolymph of insects to be used as a glycolytic fuel (Steele 1982). The glycogen content may vary depending on physiological state (Anand and Lorenz 2008) or environmental conditions (Chowanski et al. 2015).

Triacylglycerol is formed by fatty acids that can be used for energy production through $\beta$-oxidation. Lipids are always the main component of the fat body which, in insect, represents more than $50 \%$ of their dry weight (Ziegler 1991). Lipids provide energy during diapause (Hahn and Denlinger 2007), for embryo development (Ziegler and Van Antwerpen 2006) and sustained flight activity (Van der Horst 2003).

Proteins can also supply energy through catabolism and are essential in tissue building and repair. For this reason, it is also relevant to study the variability of insect protein content under different conditions.

Living organisms use reserves to maintain their bodies, growth, development, and reproduction (Arrese and Soulage 2010). Under stressful conditions, there is an increased expenditure associated with detoxification which can have a negative impact on life-history traits in the life cycle. After exposure to pesticides, it has been shown that energy reserves decreased in several insects (Ribeiro et al. 2001; Nath 2003; Da Silva 2004; Rharrabe et al. 2008).

A low level of energy reserves could potentially influence the population dynamics of earwigs and decrease their role in pest management in apple orchards. Markaw (1995) and Nestel et al. (2016) showed that ecological stressors can affect developmental instability, which leads to reduced fitness. Morphological parameters e.g. mass or insect size can be used to detect the effects of environmental stress on an organism.

The aim of our study was to assess the effects of two orchard management strategies, organic and IPM practices, on earwig ( $F$. auricularia) weight, energy reserves (glycogen, lipid and protein contents) and two morphometric parameters (inter-eye and prothorax widths).

\section{Materials and methods}

\subsection{Chemical compounds}

Sodium chloride, Tris-HCl, trichloroacetic acid, ethanol, Oyster glycogen, glucose, sodium acetate, amyloglucosidase from Aspergillus Niger, phosphovanillin, sulfuric acid and bovin serum albumin were purchased from Sigma-Aldrich ${ }^{\circledR}$ (Saint Quentin-Fallavier, France) while glucose RTU ${ }^{\mathrm{TM}}$ was purchased from bioMérieux SA ${ }^{\circledR}$ (Geneva, Suisse).

\subsection{Earwigs}

Male and female adults of $F$. auricularia L. earwigs were caught in July 2015 using cardboard traps placed on apple tree branches in five orchards located in Noves, near Avignon (south-eastern France). The landscape around these orchards is similar and characterized by the presence of a dense network of windbreak hedgerows, which protects orchards against the prevailing northern winds. Since this 
species is univoltine, these adults were of roughly the same age. The five orchards had two management strategies: three were under IPM management and thus applied synthetic plant protection products and two were under organic farming and used a restricted range of products (such as carpovirusine, spinosad, copper, sulfur...). Twenty male and 20 female earwigs were collected from each management system (i.e. 40 and 60 earwigs per sex for organic and IPM strategies, respectively), frozen and stored at $-20{ }^{\circ} \mathrm{C}$ until biochemical and morphometry measurements were carried out.

\subsection{Morphometric measurements}

Frozen earwigs were slightly thawed to avoid change to morphometric measurements. All morphometric measurements of earwigs were carried out using an eyepiece micrometer on a Nikon ${ }^{\circledR}$ binocular microscope. Measurements were first recorded as units of the ocular micrometer scale to the nearest $1 \mu \mathrm{m}$ and were then converted into $\mathrm{mm}( \pm 0.1 \mathrm{~mm})$. Each earwig was positioned carefully to avoid bias in measuring and to achieve the same plane of view. A single person carried out all the measurements to avoid user bias. We measured the maximum prothorax and inter-eye (i.e., distance between the eyes) widths. The inter-eye width was measured in a straight line between the two eyes and the prothorax width between two reference points (Fig.1).

\subsection{Scanning electron microscopy}

We used scanning electron microscope photography (Philips XL 30 ESEM with detector SE) to obtain images (e.g. Figure 1) of dried specimens coated with a gold layer of $10^{-12} \mathrm{~m}$. The equipment was set to operate at $20 \mathrm{KV}$ acceleration voltage, at 35 for the magnification and at $28.9 \mathrm{~mm}$ for the working distance.

\subsection{Crude extract preparation}

After morphometric measurements, earwigs (male and female) were weighed individually using a Precisa $^{\circledR}$ XT120A electronic precision balance with a readability of $0.1 \mathrm{mg}$. The whole body of the earwig was homogenized on ice in $10 \%(\mathrm{w} / \mathrm{v})$ low-salt buffer containing $10 \mathrm{mM}$ Tris- $\mathrm{HCl}(\mathrm{pH} 7.3)$ and $10 \mathrm{mM} \mathrm{NaCl}$ and centrifugated for $10 \mathrm{~min}$ at $3000 \mathrm{~g}$. This supernatant was the crude extract on which further glycogen, lipid or protein measurements were carried out.

\subsection{Biochemical measurements}

\section{Determination of glycogen content}

The method, based on enzymatic hydrolysis of glycogen by amyloglucosidase (EC 3.2.1.3), was used according to Parrou and François (1997). Solution trichloroacetic 4\% acid was added to $250 \mu \mathrm{l}$ of crude extract $(\mathrm{v} / \mathrm{v})$ for deproteinization and the solution was centrifuged at $3000 \mathrm{~g}$ for 1 min at $4{ }^{\circ} \mathrm{C}$. After centrifugation, two volumes of $95 \%$ ethanol were added to precipitate the glycogen, which was present in the supernatant. Glycogen was finally pelleted by centrifugation at $5000 \mathrm{~g}$ for $5 \mathrm{~min}$ at $4{ }^{\circ} \mathrm{C}$. Ethanol was removed and the pellet was dried at room temperature. The dried pellet was incubated for 
$2 \mathrm{~h}$ at $60{ }^{\circ} \mathrm{C}$ in $500 \mu \mathrm{L}$ of $0.2 \mathrm{M}$ sodium acetate, $\mathrm{pH}$ 5.2, containing $7 \mathrm{UI}$ of amyloglucosidase. After incubation, the solution was cooled on ice for $5 \mathrm{~min}$ and the amount of glucose generated from glycogen was determined using the Glucose $\mathrm{RTU}^{\mathrm{TM}}$ method adapting to 96-well microplate format. The reaction mixture $\left(275 \mu \mathrm{L}\right.$ final volume), containing $250 \mu \mathrm{L}$ Glucose $\mathrm{RTU}^{\mathrm{TM}}$ and $25 \mu \mathrm{L}$ glucose produced above, was left to stand for $20 \mathrm{~min}$ at room temperature, before glucose detection by measuring the absorbance at $505 \mathrm{~nm}$. The amount of glucose was calculated from a standard curve (A $505=\mathrm{f}$ [glucose]) containing pure glucose as a standard treated within the same conditions. Because the final values included the amount of glycogen was corrected for the glucose content in samples that were not incubated with amyloglucosidase.

\section{Determination of lipid content}

Total lipids were determined using a sulphophosphovanillin reaction according to the method of Frings et al. (1972) adapted to a 96-well microplate format. $294 \mu \mathrm{L}$ concentrated sulfuric acid was added either to $6 \mu \mathrm{L}$ of earwig crude extract or to $6 \mu 1$ of a standard solution (olive oil). The solutions were homogenized and placed in boiling water for $10 \mathrm{~min}$ and cooled on ice for $5 \mathrm{~min}$. A $700 \mu \mathrm{L}$ of the phosphovanillin reagent was added to each extract or lipid standard, homogenized and incubated at $37^{\circ} \mathrm{C}$ in a water bath for $15 \mathrm{~min}$. After the samples were allowed to cool for $5 \mathrm{~min}$ the absorbance was recorded at $540 \mathrm{~nm}$.

\section{Determination of protein content}

Total protein content was determined by the Lowry method modified according to Markwell et al. (1978), with bovine serum albumin as the standard.

The energy reserve values were derived directly from a standard curve prepared with known concentrations of bovine serum albumin, glycogen and lipid. All assays were run in triplicate.

All the above components were expressed as milligrams per $g$ of earwig.

\subsection{Statistical analysis}

For all the parameters (energy reserves and morphometric measurements), the effects of orchard management (organic vs IPM) and earwig sex were included in a mixed model with management and sex as fixed factors and apple orchard as a random factor. The assumptions of normality and homogeneity of variance were first tested, and log-transformation was applied when required (weight and morphometric measurements). We compared all the means for both factors using the 'lsmeans' package. The effects of the factor were thus assessed with the general model but sometimes also on simplified models (one factor only) depending on the significance of the interaction between the factors. All computations were carried out using R (version 2.15.3). 


\section{Results}

\subsection{Weight}

Both earwig sex and orchard management had a significant effect on earwig weight $(p<0.001)$ and no significant interaction was observed between the two factors $(p=0.37)$. Regardless of orchard management strategy, male earwigs were significantly heavier than females. The weight of both sexes of earwigs sampled in organic orchards was also higher than those sampled in IPM orchards (Fig. 2).

\subsection{Morphometric parameters}

\section{Prothorax and inter-eye widths}

Similar observations to above were obtained with the morphometric analysis of the earwigs. For both, prothorax and inter-eye widths measurements, sex did not have a significant effect, and the interaction between sex and management strategy was also not significant. Only management strategy had a significant effect with significantly smaller prothorax $(p=0.032)$ and inter-eye widths $(p=0.026)$ for earwigs sampled in IPM orchards compared to those sampled in organic orchards (Fig.3). The decrease in inter-eye width was about $3 \%$ and between 2 to $5 \%$ for the prothorax width.

3.3 Biochemical analysis

Glycogen

The interaction between sex and management strategy was highly significant $(p<0.001)$ for the glycogen content. For both management practices $(p<0.001)$ sex had a significant effect with females having higher glycogen content than males. Management practices had no overall effect but when only females were considered, higher glycogen contents were observed in earwigs from organic compared to IPM orchards. No significant difference was observed for males explaining the significant interaction.

Sex and the interaction between sex and management strategy had no significant effect on the earwig lipid contents. However, management strategy had a significant effect $(p=0.008)$ with lower lipid content in earwigs sampled in IPM orchards than those sampled in organic orchards $(23.49 \mathrm{mg} \pm 10.57$ vs $32.10 \mathrm{mg} \pm 10.39$ and $24.23 \mathrm{mg} \pm 11.12 \mathrm{vs} 29.49 \mathrm{mg} \pm 10.57$ respectively for females and males (Fig. 4 B)). On average, earwigs sampled in IPM orchards had 25 to $42 \%$ less triacylglycerol than those under organic management.

\section{Proteins}

Sex and the interaction between sex and management strategy had no significant effect on earwig protein contents. However, management strategy had a significant effect $(p=0.016)$ with higher body protein content in earwigs from IPM orchards than organic orchards (Fig. 4 C). Earwigs in IPM orchards had $70 \%$ more protein than those under organic management for both female and male. 


\section{Discussion and conclusion}

It is well recognized that agricultural management practices including the use of pesticides affects non-target species and leads to a decline in biodiversity in agroecosystems (Mac Laughlin and Mineau 1995; Kromp 1999; Nash et al. 2008). The hazard of pesticide usage depends on the application rate, intrinsic toxicity and the level of uptake, persistence, volatilization, metabolization and bioavailability of the active ingredient (Sanchez-Bayo 2009). The exposure time is also a critical variable in risk assessments of agrochemicals. Organisms may develop a number of strategies to minimize the negative toxic effects induced by chemical stress. All responses to resist toxicants are costly for the organism in terms of metabolic resources and energy demand (Calow 1991). Because the energy resources of organisms are limited and used for growth, reproduction and basal metabolism, the additional metabolic costs due to pesticide management results in a reallocation of energy resources, and can increase energy consumption leading to reduced energy reserves (Congdon et al. 2001; Yasmin and Souza 2010). Resource allocation and life history strategies are inevitably interconnected for all organisms because of the competition and the limitation of available energy reserves either in the environment or within the individual itself.

Our results confirm that pest management strategy can result in changes to energy reserves in earwigs. Our measurements of energy reserves indicated a lower lipid and glycogen contents in earwig bodies collected from IPM compared to organic orchards. The major differences between the organic and IPM strategies were lower total Treatment Frequency Index (TFI: total number of pesticide treatment weighted by the ratio of the dose used to the recommended dose (Jørgensen 1999), and agricultural practices such as tillage, total weed removal or the presence and quality of hedges in the organic orchard. In organic strategy, pest control is based on a greater use of mineral fungicides (copper and sulphur) and natural insecticides (granulovirus, mineral oils and spinosad). In contrast, non-organic orchards mainly used synthetic pesticides which are known to be more efficient against pests. Beside the fact that the total TFI, was slightly but significantly lower in organic orchards (22.2), than in IPM orchards (26.6) it has been previously shown that the earwig community of $F$. auricularia was lower in IPM orchards compared to organic orchards and was correlated to a higher insecticide use (4.9 in organic vs 9.2 in IPM) (Malagnoux et al. 2015b). By their toxicity, insecticides increase lethality and/or affect the behavior of non-target organisms. For example, high sensitivity of $F$. auricularia to many insecticides was observed after exposure to organophosphates (Ffrench-Constant and Vickerman 1985; Malagnoux et al. 2015a), pyrethrinoids (Badji et al. 2004) and neonicotinoids (Shaw and Wallis 2010; Malagnoux et al. 2015b). Moreover, insecticide exposure induced disturbed behavior in predation activity of earwigs (Malagnoux et al. 2015a), cast production of earthworms (Jouni et al. 2018), feeding rate of the white shrimp (Garcia de La Parra et al. 2006) or locomotion of zebrafish (Tilton et al. 2011). Because the process of food detection involves complex nervous activity that can 
be disrupted by neurotoxic pesticides (Desneux et al. 2007), impairments on behavior modify the feeding ability of the organisms and leads to a decrease in their energy reserves. Then, despite the possible loss in prey availability induced by higher TFI in IPM orchards (Sauphanor and Stäubli 1994; Altieri 1999; Pekar 1999; Dib et al. 2016), we assumed that the main factor responsible for depletion in energy reserves lies to a direct effect of insecticides on the organisms rather than on environmental modification (i.e. food availability). Our assumption was supported by several studies that have been conducted in laboratory experiments without food limitation. These studies have shown that exposure to organophosphorus insecticides, either severely disturbed glycogen metabolism in the Lepidoptera Bombyx mori (Nath 2003), or induced a significant depression of glycogen, lipid, and protein contents in the terrestrial isopod Porcellio dilatatus (Ribeiro et al. 2001).

Glycogen is a major glucose reserve and can be rapidly mobilized whereas lipids and proteins are considered as long-term reserves (Arrese and Soulage 2010). In our study, the protein values were higher in male and female earwigs sampled from the orchard under IPM. Our results are in agreement with those of Jeon et al. (2013) who observed an increase in protein of Daphnia magna after carbaryl exposure, associated to a decrease in lipid and carbohydrate contents, or with the results of Staempfli et al. (2007) in the soil arthropod, Folsomia candida after dinoseb exposure. Reallocation of energy reserves to maintain homeostasis under pesticide exposure mainly focuses on protein induction to improve defense mechanisms, and they often involve overproduction of detoxification enzymes (Calow 1991). According to those results and ours, it is unlikely that the increase in protein levels in IPM practices may offset the reduction in glycogen and lipid but, on the contrary, the consumption of glycogen and lipid content allow protein synthesis, which is highly cost effective. According to the thermodynamics of each nutrient (17.5 kJ/g glycogen, $24 \mathrm{~kJ} / \mathrm{g}$ protein, and $39.5 \mathrm{~kJ} / \mathrm{g}$ lipids) (Gnaiger 1983), total energy reserves are higher in term of global kJ in IPM orchards by $19 \%$ and $28 \%$ for male and female earwigs, respectively. However, this amount of energy is not available fast enough. When the organisms become unable to cope with stress or pollutants, the energy budget results of imbalance between the rate of synthesis and rate of degradation. Then, after the use of glycogen and lipids, proteins constitute the last energy reserve to change or be used upon stress exposure (Ferreira et al. 2015). In this context, studies have reported that a decrease of protein content is associated to an increase in mortality. It was the case observed by Staempfli et al. (2007) where a biphasic concentration-response linked to the phenomenon of hormesis was observed, showing that after having produced an effort to increase growth and reproduction, lethality increases. Rharrabe et al. (2008) demonstrated that for lepidoptera Plodia interpunctella Hübner, the insecticide azadirachtin caused a severe reduction in protein levels and led larval weight loss, developmental delay followed by high lethality. These authors postulated that azadirachtin exerts its effect on insects by modifying the protein synthesis capacity of the fat body as also observed for S. litura (Huang et al. 2004). Moreover, Ribero et al. (2001) observed a decrease in protein content in parathion-intoxicated isopods 
along with an increase in mortality, indicating that physiological adaptability to compensate pesticide stress requires high-energy but ineffective demand associated with. In addition to agricultural practices, other factor can have an impact on rates of energy consumption, e.g. age and environmental conditions including temperature or dehydrating state. Anurag and Lorenz (2008) reported that the cricket, Gryllus bimaculatus, fat body energy reserves were age-dependent. Climatic conditions also change abundance of energy reserves (Chowanski et al. 2015). F. auricularia is univoltine, and in south of France, earwigs reach the adult stage in early summer. It is noteworthy that because all the organisms analyzed were caught in July, they were of roughly the same age. Moreover this study was carried out on a same town and thus a reduced geographic area (less than 10 $\mathrm{km}$ radius), climatic conditions and landscape type are very similar. In this region, all orchards are surrounded by hedges due to the prevailing wind. Moreover, earwigs are nocturnal, inactive and hidden during the day inside the cardboard traps. When they are captured, we can assumed they are all in the same diet stage with an almost empty gut that will limit differences in energy reserves. Thus, in the studied apple orchards, the main factor governing energy budget in F. auricularia was assumed to be management strategy, and suggested that insecticide use, quantitatively and qualitatively, is able to decrease $F$. auricularia energy reserves. Other pollutant molecules can also lead to changes in energy reserves under natural conditions. Indeed, studies of chronically polluted with metals effects on the bettle Pterostichus oblongopunctus, showed a significant decrease in energy reserves (Bednarska et al. 2013). Givaudan et al. (2016) showed higher lipid and glycogen contents in earthworms collected in abandoned and organic orchards compared to IPM orchards. Thus, the depletion of such biochemical constituents can be due to the major mobilization of these nutrients in response to the toxic effect of the pesticides.

Biochemical parameters appear to be good biomarkers for monitoring environmental management strategies but they need to be complemented with morphological parameters to confirm the impact of orchard management practices. Weight and morphometric traits in our earwigs were lower in IPM than in organic orchards. Earwigs from IPM orchards have to make trade-offs between maintenance, growth, storage and resistance to agrochemicals so as to maximize their fitness. The observed reduction in their prothorax and inter-eye widths is likely to be the consequence of these trade-offs induced by pesticides. A lot of studies in other insects showed that pesticides can lead to morphometric variations. Marcus and Fiumera (2016) showed that exposure to atrazine, the one of the most widely used herbicides significantly affected male and female adult body size of Drosophila melanogaster. In Pterostichus melasitalicus, a carabidae, morphometric analyses also showed that dimethoate application caused a reduction in body or elytra lengths in females (Giglio et al. 2011). Giglio et al. (2017) showed in another carabidae, Calathus fuscupes, that morphological parameters e.g. body and pronotum width decreased after an exposure to the larvicide lambda-cyhalothrin. Moreover, studies of the effects of an inorganic insecticide (boric acid) against Blatella germanica showed a reduction in the size of basal oocytes, which affected its reproduction (Habes et al. 2013). 
344 All these studies suggest that agrochemical molecules can have an impact on the morphometric 345 parameters of exposed organisms.

346 Our results underline the possible modifications in biochemical and morphometric parameters in 347 earwigs due to orchard management strategies. Body energy reserves and prothorax and inter-eye 348 widths in earwigs may be interesting biomarkers to characterize changes induced by agricultural 349 farming both with pesticides and for other practices in orchards. This study shows more widely that $F$. auricularia, along with some other characteristics (ease of capture, identification, univoltine species) is an interesting potential bioindicator of the orchard management practices, especially in pip-fruit orchards, where it is considered an active natural enemy of aphids. In order to characterize the specific effects of pest management strategy on earwigs (direct and indirect effects), future studies should also be performed in abandoned orchards to assess the consequence of a free-pesticide environment. Other morphometric parameters could additionally be investigated to further determine if agricultural strategies influence other earwig life-history traits and further weakens these non-target species. In conclusion, this present study highlights the need to develop an integrated approach to assess both the physiological and biochemical modifications induced by pest management strategies on natural enemies. 
We thank Alain Tonetto (Pratim, Aix Marseille University) for assistance in taking the electronic microscopy photos. We are grateful to the Rovaltain Fundation for its financial support of the I-ResPect project.

\section{References}

Altieri MA (1999) The ecological role of biodiversity in agroecosystems. Agric Ecosyst Environ 74:19-31.

Anand A and Lorenz MW (2008) Age-dependent changes of fat body stores and the regulation of fat body lipid synthesis and mobilisation by adipokinetic hormone in the last larval instar of the cricket, Gryllus bimaculatus. J Insect physiol 54:1404-1412.

Arrese EL and Soulage JL (2010) Insect faty body: energy metabolism and regulation. Ann Rev Entomol $55: 207-225$.

Badji CA, Guedes RNC, Silva AA, Araujo RA (2004) Impact of deltamethrin on arthropods in maize under IPM and no-tillage cultivation. Crop Prot. 23 : 1031-1039.

Bednarska AJ, Stachowicz I, Kurianska L (2013) Energy reserves and accumulation of metals in the ground beetle Pterostichus oblongopunctatus from two metal-polluted gradients. Environ Sci Pollut Res $20: 390-398$.

Beenakkers AMT, Vanderhorst DJ, Vanmarrewijk WJA (1984) Insect flight metabolism. Insect Biochem 14:243-60.

Calow P (1991) Physiological costs of combating chemical toxicants: ecological implications. Comp Biochem Physiol 100(1/2) :3-6.

Campos MR, Picanço MC, Martins JC, Tomaz AC, Guedes RNC (2011) Insecticide selectivity and behavioral response of the earwig Doru luteipes. Crop Prot $30: 1535-1540$.

Chowanski S, Lubawy J, Spochacz M, Paluch E, Smykalla G, Rosinski G, Slocinska M (2015) Cold induced changes in lipid, protein and carbohydrate levels in the tropical insect Gromphadorhina coquereliana. Comp Biochem and Physiol Part A 183 : 57-63.

Congdon JD, Dunham AE, Hopkins WA, Rowe CL (2001) Resource allocation-based life histories : a conceptual basis for studies of ecological toxicology. Environ Toxicol Chem 20(8) :1698-1703.

Debras JF, Dussaud A, Rieux R, Dutoit T (2007) Prospective research on the "source" role of hedges in integrated fruit production. The case of earwigs: Forficula auricularia L. et Forficula pubescens L. Gené. C.R. Biol. 330, 664-673. (in French)

Desneux N, Decourtye A, Delpuech JM (2007) The sublethal effects of pesticides on beneficial arthropods. Annu Rev Entomol 52:81-106.

Dib H, Simon S, Sauphanor B, Capowiez Y (2010) The role of natural enemies on the population dynamics of the rosy apple aphid, Dysaphis plantaginea Passerini (Hemiptera: Aphididae) in organic apple orchards in south-eastern France. Biol. Control 55 : 97-109.

Dib H, Sauphanor B, Capowiez Y (2016) Effect of management strategies on arthropod communities in the colonies of rosy apple aphid, Dysaphis plantaginea Passerini (Hemiptera: Aphididae) in southeastern France. Agric Ecosyst Environ 216 : 203-206.

Ferreira NGC, Morgado R, Santos MJG, Soares AMVM, Loureiro S (2015) Biomarkers and energy reserves in the isopod Porcellionides pruinosus: The effects of long-term exposure to dimethoate. Sci Total Environ $502: 91-102$. 
Ffrench-Constant RH, Vickerman GP (1985) Soil contact toxicity of insecticides to the European earwig Forficula auricularia (Dermaptera). Entomophaga 30 : 271-278.

Frings CS, Fendley TW, Dunn RT, Queen CA (1972) Improved determination of total serum lipids by the sulfo-phospho-vanillin reaction. Clin Chem 18(7): 673-674.

Fountain MT, Harris AL (2015) Non-target consequences of insecticides used in apple orchards on Forficula auricularia L. (Dermaptera: Forficulidae). Biological Control 91: 27-33.

García-de la Parra LM, Bautista-Covarrubias JC, Rivera-de la Rosa N, Betancourt-Lozano M, Guilhermino L (2006) Effects of methamidophos on acetylcholinesterase activity, behavior, and feeding rate of the white shrimp (Litopenaeus vannamei). Ecotox. Environ. Safe. 65: 372-380.

Giglio A, Cavaliere F, Giulianni PG, Mazzei A, Talarica F, Vommaro ML, Brandmayr P (2017) Impact of agrochemicals on non-target species : Calthus fuscipes Goeze 1777 (Coleoptera : Carabidae) as model. Ecotox Environ Safety $142: 522-529$.

Giglio A, Giulianni PG, Zetto T, Talarica F (2011) Effects of the pesticide dimethoate on a nontarget generalist carabid, Pterostichus melas italicus (Dejean, 1828) (Coleoptera: Carabidae). Italian J Zoology 78(4) :471-477.

Gill HK and Garg H. (2014) Pesticides: Environmental impacts and management strategies. Pesticides - Toxic Aspects. pp 187-230.

Givaudan N, Suchail S, Rault M, Mouneyrac C, Capowiez Y (2016) Impact of orchard management strategies on earthworm (Allobophora chlorotica) energy reserves. Soil Biol Chem 100:252-254.

Gnaiger E. (1983) Calculation of energetic and biochemical equivalents of respiratory oxygen consumption. In: Gnaiger E, Forstner H (eds) Polarographic oxygen sensors. Aquatic and physiological applications. Springer, Berlin, pp 337-345.

Habes D, Messiad R, Gousmia S, Grib L (2013) Effects of an inorganic insecticide (boric acid) against Blattella germanica: Morphometric measurements and biochemical composition of ovaries. Afr $\mathrm{J}$ Biotech 12(18) :2492-2497.

Hahn DA, Denlinger DL. (2007) Meeting the energetic demands of insect diapause: nutrient storage and utilization. J. Insect Physiol. 53:760-73

Huang Z, Shi P, Dai,J, Du J (2004) Protein metabolism in Spodoptera litura (F.) is influenced by the botanical insecticide azadirachtin. Pest Biochem Physiol 80: 85-93.

Jeon J, Kretschmann A, Escher BI, Hollender J (2013) Charaterization of acetylcholinesterase inhibition and energy allocation in Daphnia magna exposed to carbaryl. Ecotox Environ Safety $98: 28-35$.

Jørgensen LN (1999). Denmark's action plans for pesticides: status and role of research. Nordisk Jordbrugsforskning 81: 201-202.

Kölliker M and Vancassel M (2007) Maternal attendance and the maintenance of family groups in common earwigs (Forficula auricularia): a field experiment. Ecological Entomology 32 :24-27.

Kromp B (1999) Carabid beetles in sustainable agriculture: A review on pest control efficacy, cultivation impacts and enhancement. Agric Ecosyst Environ 74:187-228.

Malagnoux L, Capowiez Y, Rault M (2015a) Impact of pesticide exposure on the predation activity of the European earwig, Forficula auricularia. Environmental Science and Pollution Research 22: 14116-14126

Malagnoux L, Marliac G, Simon S, Rault M, Capowiez Y (2015b) Management strategies in apple orchards influences earwig community. Chemosphere 124 : 156-162.

Marcus SR, Fiumera AC (2016) Atrazine exposure affects longevity, development time and body size in Drosophila melanogaster. J Insect Physiol 91-92:18-25.

Markwell MAK, Hass SM, Bieber LL, Tolbert NE (1978) A modification of the Lowry procedure to 
simplify protein determination in membrane and lipoprotein samples. Anal. Biochem. 87 : 206-210.

Martinou AF, Seraphides N, Stavrinides MC (2014) Lethal and behavioral effects of pesticides on the insect predator Macrolophus pygmaeus. Chemosphere 96 : 167-173.

Mazzia C, Pasquet A, Caro G, Thénard J, Cornic J-F, Hedde M, Capowiez Y (2015) The impacts of management strategies in apple orchards on the structural and functional diversity of epigeal spiders. Ecotoxicology 24: 616-625.

Mclaughlin, Mineau P (1995) The impact of agricultural practices on biodiversity. Agric Ecosyst Environ 55 :201-2012.

Moerkens R, Leirs H, Peusens G, Belien T, Gobin B (2012) Natural and human causes of earwig mortality during winter: temperature, parasitoids and soil tillage. J. Appl. Entomol. $136: 490-500$.

Nash MA, Thomson LJ, Hoffmann AA (2008) Effect of remnant vegetation, pesticides, and farm management on abundance of the beneficial predator Notonomus gravis (Chaudoir) (Coleoptera: Carabidae). Biol Control 46: 83-93.

Nath BS (2003) Shifts in glycogen metabolism in hemolymph and fat body of the silkworm, Bombyx mori (Lepidoptera: Bombycidae) in response to organophosphorus insecticides toxicity. Pest Biochem Physiol $74: 73-84$.

Nestel ND, Papadopoulos NT, Pascacio-Villafán C, Righini N, Altuzar-Molina AR, Aluja M (2016) Resource allocation and compensation during development in holometabolus insects. J Insect Physiol 95:78-88.

Parrou JL and François J (1997) A simplified procedure for a rapid and reliable assay of both glycogen and trehalose in whole yeast cells. Anal Biochem 248:186-188.

Pekar S (1999) Effect of IPM practices and IPM spraying on spider population dynamics in an apple orchard. Agric Ecosyst Environ 26 : 155-166.

Rharrabe K, Amri H, Bouayad N, Sayah F (2008) Effects of azadirachtin on post-embryonic development, energy reserves and a-amylase activity of Plodia interpunctella Hübner (Lepidoptera: Pyralidae). J Stored Prod Res 44 :290-294.

Ribeiro S, Sousa JP, Nogueira AJA, Soares AMVM (2001) Effect of Endosulfan and Parathion on Energy Reserves and Physiological Parameters of the Terrestrial Isopod Porcellio dilatatus. Ecotox Environ Safety $49: 131-138$.

Romeu-Dalmau C, Pinol J, Espadaler X (2012) Friend or foe? The role of earwigs in a Mediterranean organic citrus orchard. Biol Control $63: 143-149$.

Sánchez-Bayo F (2009) From simple toxicological models to prediction of toxic effects in time. Ecotoxicology 18:343-354.

Sauphanor B, Stäubli A (1994) Evaluation au champ des effets secondaires des pesticides sur Forficula auricularia et Anthocoris nemoralis: validation des résultats de laboratoire. In: Vogt, H. (Ed.), OILB-SROP Section Régionale Ouest Paléarctique, Pesticides and beneficial organisms, vol. 17. Bulletin OILB/SROP, pp. 83-88.

Sauphanor B, Dirwimmer C, Boutin S, Chaussabel AL, Dupont N, Fauriel J, Gallia V, Lambert N, Navarro E, Parisi L, Plenet D, Ricaud V, Sagnes JL, Sauvaitre D, Simon S, Speich P, Zavagli F (2009) Comparative analysis of different systems in fruit tree farming. In: INRA (Ed.), Ecophyto R\&D: Towards crop management systems that save crop protection products, Expert report, Volume IV, National Institute of Agronomic Research.

Sauphanor B. (1992). An aggregation pheromone in the European earwig Forficula auricularia L. Entomol Exp Applic 62 (3): 285-291.

Sharley DJ, Hoffmann AA, Thomson LJ (2008) The effects of soil tillage on beneficial invertebrates within the vineyard. Agric. For. Entomol. $10: 233-243$. 
500 Shaw PW, Wallis DR (2010) Susceptibility of the European earwig, Forficula auricularia, to 501 insecticides residues on apple leaves. New Zeland Plant Prot. 63 : 55-59.

502 Staempfi C, Tarradellas J, Becker-van Slooten K (2007) Effects of dinoseb on energy reserves in the 503 soil arthropod Folsomia candida. Ecotox Environ Safety 68 :263-271.

504 Steele JE (1982) Glycogen phosphorylase in insects. Insect Biochem. 12 (2) :131-147.

505 Tilton FA, Bammler TK, Gallagher EP (2011) Swimming impairment and acetylcholinesterase 506 inhibition in zebrafish exposed to copper or chlorpyrifos separately, or as mixtures. Comp. Biochem. 507 Phys. C. 153: 9-16.

508 Yasmin S and Souza D (2010) Effects of pesticides on the growth and reproduction of earthworm: A 509 review Applied and Environmental Soil Science 1-9. doi:10.1155/2010/678360.

510 Ziegler R (1991) Changes in lipid and carbohydrate metabolism during starvation in adult Manduca 511 sexta. J Comp Physiol Part B $161: 125-131$.

512 Ziegler R, Van Antwerpen R. (2006). Lipid uptake by insect oocytes. Insect Biochem. Mol. Biol. $513 \quad 36: 264-72$. 
Figure 1. Scanning electron microscopy dorsal view of head and prothorax of a male earwig showing the measurement method applied to selected body parts: the inter-eye (A) and the prothorax (B).

Figure 2. Mean weight (+SE) of the female and male adults of earwigs depending on the management strategy in apple orchards. ( $\mathrm{n}=40$ for male and $\mathrm{n}=40$ for females for each strategy).

Figure 3. Measurements of morphometric parameters: prothorax and inter-eye widths (means $+\mathrm{SE}$ ) according to the management strategy in apple orchards. For each morphometric parameter, bars with the same letters are not significantly different form each other $(n=40$ for males and females for each strategy).

Figure 4. Energy reserves content of the female and male of earwigs for each management strategy in apple orchards. A: Glycogen, B: lipid and C: protein. Data represent the means (+SE). Bars with the same letters are not significantly different form each other $(n=40$ for males and females for each strategy). 